\title{
MYOCARDIAL PARASITE PERSISTENCE IN CHRONIC CHAGASIC PATIENTS
}

\author{
NESTOR AÑEZ, HUGO CARRASCO, HENRY PARADA, GLADYS CRISANTE, AGUSTINA ROJAS, CARMEN \\ FUENMAYOR, NESTOR GONZALEZ, GLORIA PERCOCO, RAFAEL BORGES, \\ PALMIRA GUEVARA, AND JOSE LUIS RAMIREZ \\ Facultad de Ciencias, Instituto de Cardiologia, Instituto de Investigaciones Odontológicas, Unidad de Anatomía Patológica, \\ Instituto de Estadistica Aplicada y Computación, Universidad de Los Andes, Mérida, Venezuela; Groupo de Genética Molecular, \\ Universidad Central de Venezuela, Caracas, Venezuela; Hospital Luis Razetti, Barinas, Venezuela
}

\begin{abstract}
The persistence of Trypanosoma cruzi tissue forms was detected in the myocardium of seropositive individuals clinically diagnosed as chronic chagasic patients following endomyocardial biopsies (EMBs) processed by immunohistochemical (peroxidase-anti-peroxidase [PAP] staining) and molecular (polymerase chain reaction [PCR]) techniques. An indirect immunofluorescent technique revealed antigenic deposits in the cardiac tissue in 24 (88.9\%) of 27 patients. Persistent T. cruzi amastigotes were detected by PAP staining in the myocardium of 22 (84.6\%) of 26 patients. This finding was confirmed with a PCR assay specific for $T$. cruzi in 21 (91.3\%) of 23 biopsy specimens from the same patients. Statistical analysis revealed substantial agreement between PCR and PAP techniques $(\mathrm{k}=0.68)$ and the PCR and any serologic test $(\mathrm{k}=0.77)$. The histopathologic study of EMB specimens from these patients revealed necrosis, inflammatory infiltrates, and fibrosis, and made it possible to detect heart abnormalities not detected by electrocardiogram and/or cineventriculogram. These indications of myocarditis were supported by the detection of $T$. cruzi amastigotes by the PAP technique or its genome by PCR. They suggest that although the number of parasites is low in patients with chronic Chagas' disease, their potential for heart damage may be comparable with those present during the acute phase. The urgent necessity for testing new drugs with long-term effects on $T$. cruzi is discussed in the context of the present results.
\end{abstract}

In the neotropical region, perhaps the most restricted of the endemic protozoan diseases is American human trypanosomiasis, caused by Trypanosoma (Schizotrypanum) cruzi (Chagas, 1909) and transmitted by Reduviidae-Triatomine bugs, which are found only on the American continent. When an infection by $T$. cruzi occurs in susceptible people, it may result in Chagas' disease, which is a major health problem in Latin America, judging by the 90 million people living at risk for this disease. ${ }^{1}$

Chagas' disease is characterized by both an acute and a chronic phase. The former is an active infection showing blood-circulating flagellates known as trypomastigotes, as well as amastigotes, the non-flagellated form found within several tissues including the myocardium. Clinically, in the acute phase several symptomatic patterns are present, but totally asymptomatic cases are not uncommon., ${ }^{2,3}$ The presence of specific antibodies against circulating forms of the parasite in the form of anti-T. cruzi $\operatorname{IgM}$ are normally found at a high level during the course of the acute phase. ${ }^{3,4}$ The chronic phase occurs 1-2 months after the end of the acute phase and has been traditionally divided into three forms: indeterminate, which is a symptomless period in the absence of parasites; cardiac, which involves heart damage; and digestive, which is characterized by the presence of enlarged organs known as megaesophagus or megacolon. ${ }^{5}$ Like the acute phase, the chronic phase is associated with a specific humoral response in which IgG predominates, which permits the serodiagnosis of Chagas' disease. ${ }^{3}$

One of the more identifiable signs of the cardiac form of chronic Chagas' disease is myocarditis, which according to recent observations appears to be a continuous histopathologic process starting during the acute phase ${ }^{6}$ and progressing in some cases to congestive heart failure and/or sudden death. ${ }^{7,8}$ The virtual absence of blood parasites and the difficulty in their detection in the myocardium during the chronic phase has led many workers to propose the existence of an autoimmune degenerative process as the cause of car- diac disturbances observed in patients with chronic disease. ${ }^{8}$ In contrast, there are reports of the presence of $T$. cruzi in the myocardium of patients with chronic Chagas' disease, ${ }^{9}$ and a correlation between the number of parasites detected and the extent of cardial inflammation at the same site. ${ }^{10} \mathrm{On}$ the other hand, the persistence of $T$. cruzi or a portion of its genome has recently been revealed by the polymerase chain reaction (PCR) in the cardiac tissue of autopsy specimens from chronic chagasic patients. ${ }^{11}$ The use of these modern approaches in the detection of $T$. cruzi has made it easier to detect lesion-associated parasite persistence in chronic chagasic patients, which is demonstrable only in $30 \%$ of the cases by routine microscopic analysis. ${ }^{12,13}$ The present paper deals with the persistence of $T$. cruzi in the myocardium of chronic chagasic patients using routine methodology, as well as endomyocardial biopsies (EMBs) performed on 18 untreated patients and on 10 patients at different times after treatment, using histopathologic, immunohistochemical (peroxidase-anti-peroxidase [PAP]), and molecular (polymerase chain reaction $[\mathrm{PCR}])$ techniques.

\section{MATERIALS AND METHODS}

Patients. Twenty-eight chronic chagasic patients were evaluated during the present study. Eighteen of these untreated individuals classified as having chronic disease according to clinical and serologic diagnoses during the period 1985-1996. ${ }^{14}$ This group was composed of 13 men $(72.2 \%)$ and five women $(27.8 \%)$ with a mean \pm SD age of $44.6 \pm$ 9 years (range $=34-63$ years). The other 10 patients were treated with benznidazole ( $5 \mathrm{mg} / \mathrm{kg} /$ day for 60 days) after they had been clinically and seroparasitologically diagnosed as cases with acute disease. These patients were part of a previous study carried out on 59 acute-phase patients from areas of western Venezuela where Chagas' disease is endemic. ${ }^{2}$ This group of patients (five males and five females) had a mean $\pm \mathrm{SD}$ age of $30 \pm 13$ years (range $=12-51$ years). 
The complete group consisted of 19 males (67.9\%) and nine females $(32.1 \%)$ with a mean \pm SD age of $38 \pm 12$ years (mean 38.5 years for males and 37.2 years for females, range $=12-63$ years). After written consent was obtained from all the patients to carry out the evaluation, they were subjected to a study plan similar to that carried out during the acute phase. ${ }^{2}$ Patients were classified on the basis of a clinical examination according to their degree of myocardial damage using established criteria. ${ }^{14,15}$ The study was approved by the Biomedical Committee of the National Research Council in Venezuela.

Sample collection and processing. After clinical examination at the cardiovascular center at the University of Los Andes (Merida, Venezuela), a peripheral blood sample was obtained from each patient for routine parasitologic and serologic testing. In addition, a septal EMB was obtained following the technique used by Carrasco and others ${ }^{15}$ for immunohistochemical, histopathologic, and molecular diagnosis. The parasitologic methods used were hemoculture and xenodiagnosis. ${ }^{2}$ The serologic tests used to detect circulating anti- $T$. cruzi antibodies were a direct agglutination test (DAT) with 2-mercaptoethanol, an indirect immunofluorescence antibody test (IFAT), and an ELISA. Conditions and procedures for serologic and parasitologic methods have been given elsewhere. ${ }^{2}$ Two immunohistochemical methods were used to study the EMB: an indirect immunofluorescence test (IIT) for tissue samples to detect antigenic deposits on cardiac tissue using specific antibodies contained in serum sample from the same patient, and a PAP technique for detecting $T$. cruzi amastigotes in a heart sample. ${ }^{16}$ Both tests were performed on biopsy specimens fixed in $10 \%$ buffered formaldehyde, embedded in paraffin, sectioned (2$5 \mu$ ), placed on a glass slide covered with poly-L-lysine (1: 9 ), dried overnight, and then processed for either technique. Observations were made with a Zeiss (Jena, Germany) Axioscop DIC light microscope fitted with an HBO 50 fluorescent lamp and a MC80 camera. The histopathologic study was carried out with $4 \mu$-thick sections obtained as indicated, stained with hematoxylin and eosin and Masson's trichrome, and studied by light microscopy. The myocardial damage observed in the biopsy specimens was classified following the Dallas criteria ${ }^{17}$ and a recently proposed classification. ${ }^{18}$ The sections of the EMBs were examined by a pathologist with no previous patient information and were graded on the basis of the presence of necrosis, inflammatory infiltrate, and fibrosis.

The molecular diagnosis used a PCR on 1-2 $\mathrm{mm}^{3} \mathrm{EMB}$ specimens. For DNA isolation, the sample was washed in a sterile saline solution and incubated at $55^{\circ} \mathrm{C}$ overnight in $1 \times$ Taq polymerase buffer $(50 \mathrm{mM} \mathrm{KCl}, 10 \mathrm{mM}$ Tris- $\mathrm{HCl}, 1 \%$ Triton X-100, $100 \mathrm{mg} / \mathrm{ml}$ of gelatin, $\mathrm{pH}$ 8.3) without $\mathrm{Mg}^{++}$ and proteinase $\mathrm{K}(100 \mu \mathrm{g} / \mathrm{ml})$. The following morning samples were incubated at $94^{\circ} \mathrm{C}$ for $15 \mathrm{~min}$ and the cellular debris was removed by centrifugation for $5 \mathrm{~min}$ at $1,200 \times \mathrm{g}$. The supernatant was kept at $-20^{\circ} \mathrm{C}$ until used. Two microliters of this supernatant was used for the PCR. The T. cruzispecific forward (5'-GTCGGAGCAGGGACAG-3') and reverse (5'-CCCTCTCCAAGGTCTACA-3') primers were used. These primers target sequence-repeated elements within the $T$. cruzi nontranscribed ribosomal spacer. ${ }^{19}$ The assay detected all $T$. cruzi isolates, but did not react with $T$. ran- geli, other kinetoplastida, or human DNA. ${ }^{19,20}$ The reaction was done in a total volume of $50 \mu$ containing $1 \mathrm{mM}$ of each DNTP, $200 \mathrm{mM}$ of each primer; one unit of Taq DNA polymerase in $1 \times$ reaction buffer $(10 \mathrm{~m}$ MTris-HCI, pH 8.3, $50 \mathrm{mM} \mathrm{KCl}, 100 \mathrm{mg} / \mathrm{ml}$ of gelatin). The $\mathrm{MgCl}_{2}$ concentration was adjusted to $3 \mathrm{mM}$ in each sample. The PCR was carried out in a Perkin-Elmer (Norwalk, CT) model 2,400 thermocycler and was programmed as follows: one cycle for $6 \mathrm{~min}$ at $95^{\circ} \mathrm{C}$; a second cycle for $1 \mathrm{~min}$ at $55^{\circ} \mathrm{C}, 1.5 \mathrm{~min}$ at $72^{\circ} \mathrm{C}$, and $1 \mathrm{~min}$ at $94^{\circ} \mathrm{C}$ (repeated 10 times); a third cycle for $1 \mathrm{~min}$ at $55^{\circ} \mathrm{C}, 1.5 \mathrm{~min}$ at $72^{\circ} \mathrm{C}$, and $1 \mathrm{~min}$ at $92^{\circ} \mathrm{C}$ (repeated 20 times); and a final cycle for $10 \mathrm{~min}$ at $72^{\circ} \mathrm{C}$.

To obtain the digoxigenin-labeled probe, a similar reaction was performed as that done for the PCR; $10 \mathrm{ng}$ of the plasmid PIGS3 was combined with $0.5 \mu \mathrm{l}$ of digoxigenin 11dUTP (Boehringer Mannheim, Mannheim, Germany). This plasmid is a subclone of recombinant bacteriophage 4a 1 isolated from a genomic library of $T$. cruzi isolate G. ${ }^{19}$ Trypanosoma cruzi CL Brener purified $\mathrm{DNA}^{21}$ was used as a positive control for the PCR.

Samples from a nonchagasic patient with a primary dilated myocardiopathy and a French national who had never visited an endemic area and had died in an accident were used as controls. The former patient was parasitologically and serologically negative by the same methods used to diagnose chagasic patients. A heart sample was obtained during an autopsy of the latter patient. Both samples were treated similar to those of the chronic chagasic patients for immunohistochemical, histopathologic, and molecular methodology.

Statistical analysis. Statistical analysis consisted of a comparison of the PCR and PAP as gold standard tests, and the DAT, IFAT, ELISA, blood-circulating parasite test, and the IIT as alternative tests. Comparison between any methodologic pair included estimation of sensitivity, specificity, kappa coefficient, positive likelihood ratio, and negative likelihood ratio. The kappa (к) coefficient ${ }^{22}$ was used to estimate the agreement between the gold standard and alternative tests. It was interpreted using the classification provided by Landis and Koch. ${ }^{23}$ Interpretation of likelihood followed the recommendations of Jaeschke and others. ${ }^{24}$

\section{RESULTS}

Clinical classification. The clinical examination of the 28 chronic chagasic patients revealed no heart disease in 11 $(39.3 \%$ ) (group ChM/IA) on the basis of no clinical or electrocardiographic evidence of myocardial damage. Of these, eight had been treated with benznidazole. The second group of three chronic chagasic patients $(10.7 \%)$, identified as group $\mathrm{ChM} / \mathrm{IB}$, showed normal clinical and electrocardiographic functions. However, the finding of abnormal left cineventriculograms classified them as patients with an early segmental myocardial damage. One of them had been treated with benznidazole. In the group identified as ChM/II, nine patients $(32.1 \%)$ showed abnormal resting electrocardiograms (ECGs) in which arrythmias and conduction defects were found. One of these had been treated with benznidazole. These patients showed advanced myocardial damage without congestive heart failure. The remaining five $(17.9 \%)$ chronic chagasic patients classified as group ChM/III 
TABLE 1

Diagnostic evidence in chronic chagasic patients from endemic areas of western Venezuela

\begin{tabular}{|c|c|c|c|c|c|c|c|c|c|c|c|c|}
\hline \multirow{3}{*}{$\begin{array}{l}\text { Patient } \\
\text { code }\end{array}$} & \multirow{3}{*}{$\begin{array}{l}\text { Clinical } \\
\text { condition }\end{array}$} & \multicolumn{7}{|c|}{ Diagnosis* } & \multirow{2}{*}{\multicolumn{3}{|c|}{ Pathologic finding $\dagger$}} & \multirow{3}{*}{$\begin{array}{c}\text { Clinical } \\
\text { classification }\end{array}$} \\
\hline & & \multicolumn{3}{|c|}{ Serologic } & \multirow{2}{*}{$\begin{array}{l}\text { Parasito- } \\
\text { logic } \\
\text { BCP }\end{array}$} & \multicolumn{2}{|c|}{$\mathrm{IHC}$} & \multirow{2}{*}{$\begin{array}{l}\text { - Molecular - } \\
\text { PCR }\end{array}$} & & & & \\
\hline & & DAT & IFAT & ELISA & & IIT & PAP & & $\mathrm{N}$ & II & $\mathrm{F}$ & \\
\hline $5-89 \S$ & Chronic & + & + & ND & - & + & + & + & ++ & ++ & +++ & $\mathrm{ChM} / \mathrm{IA}$ \\
\hline $1-90 \S$ & Chronic & + & + & + & - & + & + & + & ++ & ++ & + & ChM/IA \\
\hline $7-94 \S$ & Chronic & + & + & + & - & + & + & + & +++ & +++ & - & $\mathrm{ChM} / \mathrm{II}$ \\
\hline $10-94 \S$ & Chronic & + & + & + & - & + & + & ND & ++ & ++ & - & $\mathrm{ChM/IA}$ \\
\hline $11-94 \S$ & Chronic & + & + & + & - & + & - & + & +++ & +++ & + & $\mathrm{ChM} / \mathrm{IB}$ \\
\hline $3-95$ & Chronic & + & + & + & - & + & + & + & ++ & ++ & ++ & $\mathrm{ChM} / \mathrm{IB}$ \\
\hline $4-95$ & Chronic & + & + & + & - & + & + & UD & ++ & ++ & + & ChM/IA \\
\hline $20-95$ & Chronic & + & + & + & - & + & - & + & +++ & +++ & - & $\mathrm{ChM} / \mathrm{II}$ \\
\hline $29-95$ & Chronic & + & + & + & - & + & + & + & ++ & ++ & - & ChM/III \\
\hline $30-95$ & Chronic & + & + & - & - & + & + & ND & ++ & ++ & + & ChM/III \\
\hline $33-95$ & Chronic & + & + & - & - & + & + & + & - & + & + & ChM/IA \\
\hline $34-95 \S$ & Chronic & + & + & + & - & + & + & + & ++ & ++ & + & ChM/IA \\
\hline $35-95 \S$ & Chronic & + & + & + & - & + & + & + & ++ & ++ & + & ChM/IA \\
\hline $36-95 \S$ & Chronic & + & + & + & - & + & + & + & ++ & ++ & + & ChM/IA \\
\hline $37-95 \S$ & Chronic & + & + & + & - & + & + & + & +++ & +++ & - & ChM/IA \\
\hline $12-96 \S$ & Chronic & + & + & + & - & - & + & + & +++ & +++ & + & ChM/IA \\
\hline $18-96$ & Chronic & + & + & + & - & + & + & + & ++ & ++ & + & ChM/II \\
\hline $21-96$ & Chronic & + & + & + & - & + & + & ND & + & + & +++ & $\mathrm{ChM} / \mathrm{III}$ \\
\hline $22-96$ & Chronic & + & + & + & - & + & + & ND & - & - & +++ & $\mathrm{ChM} / \mathrm{II}$ \\
\hline $29-96$ & Chronic & + & + & + & - & ND & ND & + & ++ & ++ & + & $\mathrm{ChM} / \mathrm{II}$ \\
\hline $31-96$ & Chronic & + & + & + & - & + & + & + & ++ & ++ & - & ChM/II \\
\hline $13-97$ & Chronic & + & + & + & - & + & ND & + & +++ & +++ & - & $\mathrm{ChM} / \mathrm{II}$ \\
\hline $19-97$ & Chronic & + & + & + & - & + & + & ND & - & - & - & ChM/IA \\
\hline $20-97$ & Chronic & + & + & + & - & - & - & + & ++ & ++ & - & $\mathrm{ChM} / \mathrm{IB}$ \\
\hline $21-97$ & Chronic & + & + & + & - & + & - & - & +++ & +++ & ++ & $\mathrm{ChM} / \mathrm{III}$ \\
\hline $23-97$ & Chronic & + & + & + & - & - & + & + & ++ & ++ & + & CHM/II \\
\hline $26-97$ & Chronic & + & + & + & - & + & + & + & ++ & ++ & ++ & CHM/II \\
\hline $31-97$ & Chronic & + & + & & - & + & + & + & - & - & - & $\mathrm{ChM} / \mathrm{III}$ \\
\hline Control & PDCMP & - & - & - & - & - & - & - & & & & $\mathrm{NCh}$ \\
\hline Control & Normal & ND & ND & ND & ND & - & - & - & - & - & - & $\mathrm{NCh}$ \\
\hline Total $=28$ & $\%$ & 100 & 100 & 92 & 0 & 88 & 84 & 91 & 86 & 89 & 64 & \\
\hline
\end{tabular}

showed clinical signs of congestive heart failure with evident abnormal resting ECGs and abnormal left cineventriculograms. None of them had been treated with benznidazole. The clinical classification of the 28 chronic chagasic patients according to Carrasco and others ${ }^{14}$ is shown in Table 1, which is combined with other diagnostic evidence of the disease to give a general picture of each individual chronic case.

Diagnostic evidence in chronic chagasic patients: seroparasitologic findings. No blood-circulating trypomastigotes of $T$. cruzi was detected in any of the chronic chagasic patients when xenodiagnosis and hemoculture were used as parasitologic methods. Serologic tests showed that all chronic chagasic patients were seropositive for $T$. cruzi infection.

Immunohistochemical findings. When immunohistochemical techniques (IIT) were applied to the EMB specimens, antigenic deposits were detected in the cardial tissues of $24(88.9 \%)$ of 27 chronic chagasic patients. Figure 1 shows a section of an EMB specimen in which immunofluorescent deposits are observed between the cardiac fibers. The PAP technique revealed persistent parasites in cardiac tissue in $22(84.6 \%)$ of 26 chronic chagasic patients. Figure 1 also shows $T$. cruzi amastigotes in an EMB specimen stained with the PAP technique.
Detection of $T$. cruzi DNA by the PCR. The presence of parasites in EMB specimens of chronic chagasic patients was also confirmed with a PCR assay specific for T. cruzi DNA. This assay amplified 130 basepairs within the ribosomal spacer of the parasite, which made it possible to detect a portion of $T$. cruzi genome in 21 of 23 biopsy specimens $(91.3 \%)$. As shown in Figure 2, most positive biopsy specimens showed a strong PCR signal with the expected band size, whereas the negative control and a sample taken from a person who had never lived in an area endemic for Chagas' disease showed no signal.

Statistical analysis showed substantial agreement between the PCR and PAP tests $(\kappa=0.68)$ and the PCR and any serologic test $(\kappa=0.77)$. Details on the sensitivity, specificity, and likelihood between the gold standard and alternative tests are given in Table 2.

Histopathologic findings. This study showed necrosis, inflammatory infiltrates, and fibrosis in $85.7 \%, 89.3 \%$, and $64.3 \%$ of the 28 chronic chagasic patients, respectively. Severe necrosis and inflammatory infiltrates were detected in $29.2 \%$ and $28 \%$ of the patients, respectively. Moderate necrosis and inflammatory infiltrates were the most common findings, being observed in 16 patients, while mild necrosis and inflammatory infiltrates were detected in only one (4\%) 

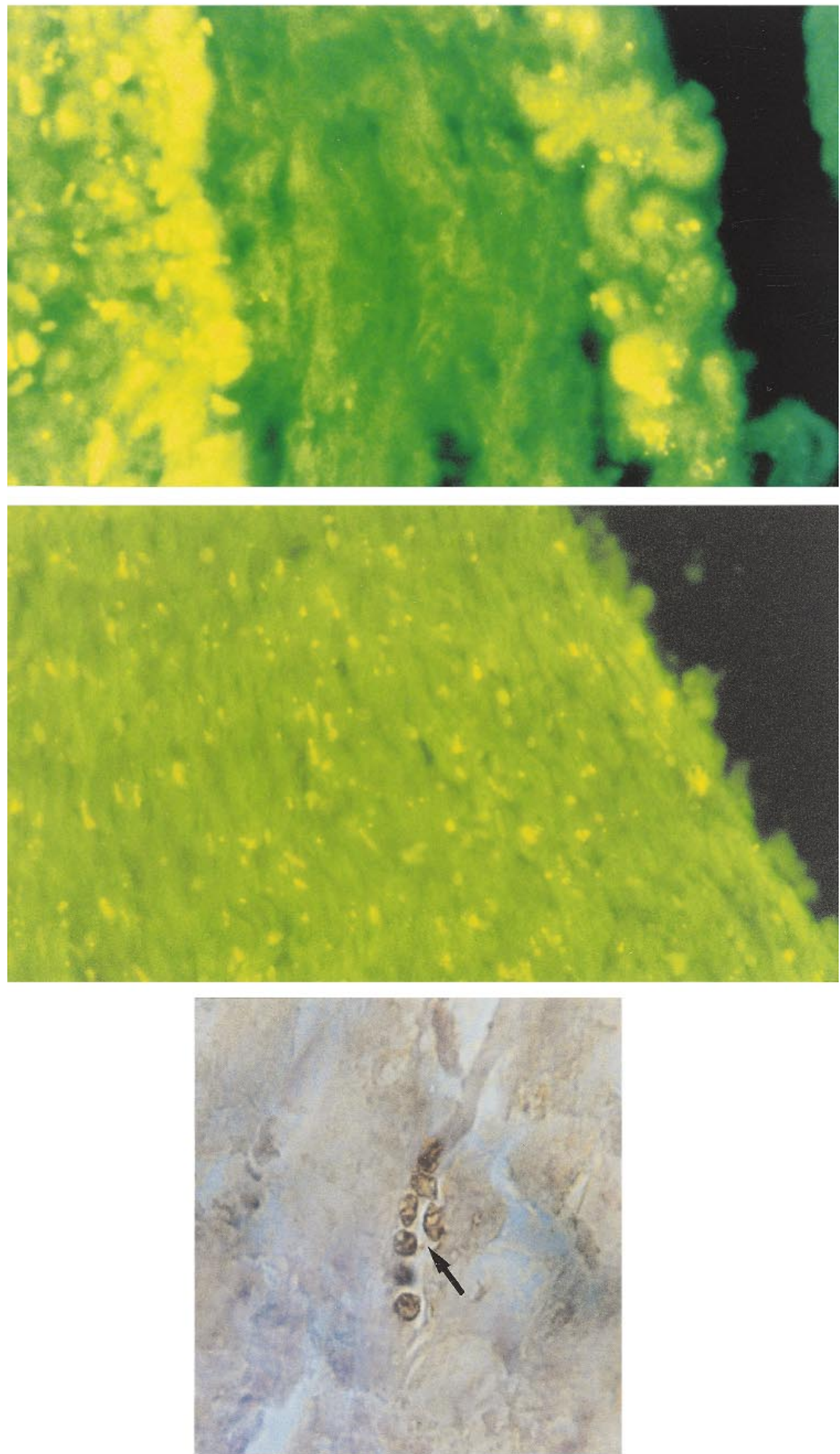

FIGURE 1. Immunohistochemical analysis of paraffin-embedded septal endomyocardial biopsy specimens of patients with chronic Chagas' disease. Top, Trypanosoma cruzi immunofluorescent antigen deposits detected by an indirect immunofluorescence test in cardial tissue. Middle, negative control. Bottom, persistent $T$. cruzi amastigotes in the myocardium detected by immunoperoxidase staining, showing a few parasites (arrow). (Magnification $\times 1,000$.) 
$\begin{array}{lllllllllll}1 & 2 & 3 & 4 & 5 & 6 & 7 & 8 & 9 & 10 & 11\end{array}$

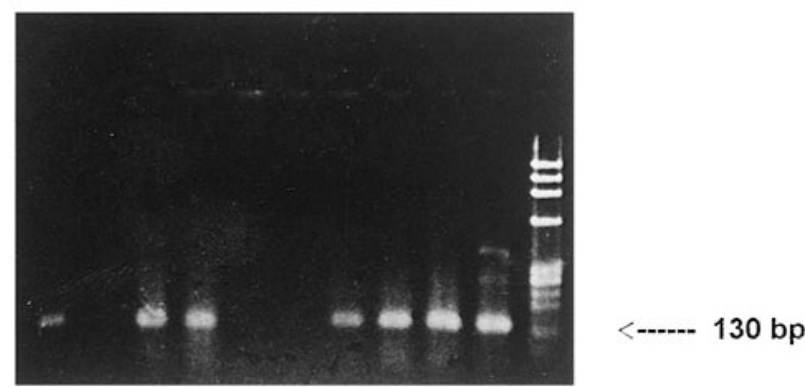

$\begin{array}{llllllllll}12 & 13 & 14 & 15 & 16 & 17 & 18 & 19 & 20 & 21\end{array}$

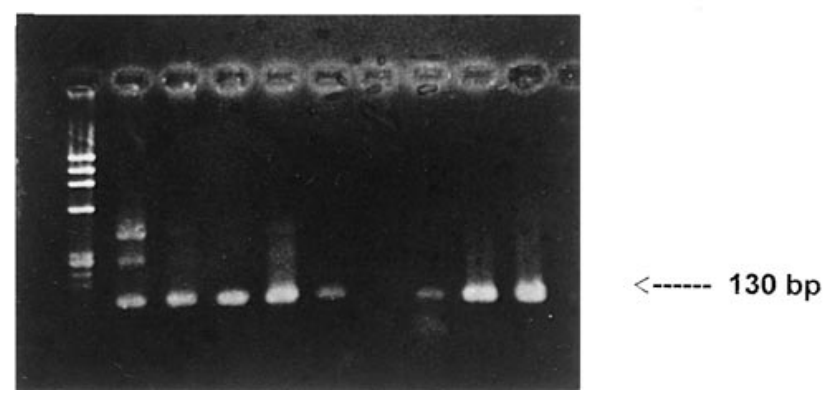

FIGURE 2. Trypanosoma cruzi species-specific polymerase chain reaction (PCR) assay on cardiac biopsy specimens. Ethidium bromide-stained gels showing PCR amplification products. Lanes 1, 3, $4,7,8,9,10,13,14,15,16,17,19$, and 20, biopsy specimens from patients with confirmed chronic Chagas' disease; lanes 2 and 5, negative biopsy specimens; lane 6 , postmortem cardiac biopsy specimen of a noninfected individual; lane 18, negative control for reagents; lane 21, product of the PCR assay on T. cruzi CL Brener purified DNA used as positive control; lanes 11 and 12, molecular weight marker. bp = basepairs.

and two (8\%) patients, respectively. Details on these individuals are given in Table 1 . With regard to fibrosis, which was the most common finding in these patients, histologic analysis of $28 \mathrm{EMB}$ specimens showed positive results in 18 (64.3\%) patients, with severe, moderate, and mild conditions found in $16.7 \%, 16.7 \%$ and $66.6 \%$, respectively (Table 1).
DISCUSSION

The present work has shown the presence of $T$. cruzi antigenic deposits, the parasite itself, or part of its genome in the myocardium of $27(96.4 \%)$ of 28 chronic chagasic patients from different localities of western Venezuela where Chagas' disease is endemic. Detecting persistent $T$. cruzi amastigote tissue forms in the hearts of cases with chronic diseases was made possible using methods based on new biotechnology that allowed the sampling and the specific identification of the parasite in those patients previously diagnosed by classical routine methods of having $T$. cruzi infections. These include the EMB, a low-risk heart invasive method, ${ }^{15}$ which when combined with the molecular PCR system, the most sensitive technique available for direct detection of T.cruzi in patients with Chagas' disease, ${ }^{25}$ and the PAP technique, a highly specific immunohistochemical technique, ${ }^{16}$ made it possible to accurately identify the presence of T.cruzi in the myocardium of these patients.

These findings are in contrast with those of earlier investigators for whom demonstration of $T$. cruzi in cardiac tissue by routine microscopy in these patients was difficult, leading them to conclude that persistent parasites are not required for chronic disease. ${ }^{26}$ The fact that autoimmune responses in patients with chronic disease have been detected as crossreactivity between $T$. cruzi antigens and host tissues ${ }^{12}$ or $T$. cruzi anti-idiotypic interactions ${ }^{27}$ has led several investigators to state that the autoimmune phenomenon occurs in the absence of the parasite, questioning the direct role of $T$. cruzi in the production of late cardiac injury. ${ }^{12}$ However, other investigators have confirmed the presence of a portion of the parasite genome or $T$. cruzi amastigotes in the myocardium of autopsied patients with chronic disease using the PAP and PCR techniques, respectively. ${ }^{11,28}$ This persistence appears to be the reason for the infrequent detection of parasitemia in cases with chronic disease when methods such as xenodiagnosis and/or hemoculture are used. In the absence of any data, the detection of patent parasitemia in patients with chronic disease may be interpreted as the discharge of trypomastigote forms into the peripheral blood from the transforming amastigote tissue forms persisting in the heart. Although there is some evidence based on autopsy specimens of the presence of $T$. cruzi during the entire life of an infected human host, to the best of our knowledge, the present

TABLE 2

Statistical comparison between different tests used in the study*

\begin{tabular}{|c|c|c|c|c|c|c|c|}
\hline $\begin{array}{c}\text { Gold standard } \\
\text { test }\end{array}$ & $\begin{array}{l}\text { Alternative } \\
\text { test }\end{array}$ & No. & Sensitivity & Specificity & $\begin{array}{c}\text { Kappa } \\
\text { coefficient }\end{array}$ & $\begin{array}{c}\text { Positive } \\
\text { LR }\end{array}$ & $\underset{\text { LR }}{\text { Negative }}$ \\
\hline PCR & DAT & 20 & 100.00 & 66.67 & 0.77 & 3.00 & 0.00 \\
\hline PCR & IFAT & 20 & 100.00 & 66.67 & 0.77 & 3.00 & 0.00 \\
\hline PCR & ELISA & 19 & 100.00 & 66.67 & 0.77 & 3.00 & 0.00 \\
\hline PCR & BCP & 19 & 0.00 & 100.00 & 0.00 & $\dagger$ & 1.00 \\
\hline PCR & IIT & 19 & 87.50 & 66.67 & 0.48 & 2.63 & 0.19 \\
\hline PCR & PAP & 18 & 86.67 & 100.00 & 0.68 & $\dagger$ & 0.13 \\
\hline PAP & DAT & 28 & 100.00 & 42.86 & 0.53 & 1.75 & 0.00 \\
\hline PAP & IFAT & 28 & 100.00 & 42.86 & 0.53 & 1.75 & 0.00 \\
\hline PAP & ELISA & 27 & 95.00 & 28.57 & 0.29 & 1.33 & 0.18 \\
\hline PAP & BCP & 28 & 0.00 & 100.00 & 0.00 & $\dagger$ & 1.00 \\
\hline PAP & IIT & 28 & 90.48 & 57.14 & 0.50 & 2.11 & 0.17 \\
\hline
\end{tabular}

$* \mathrm{LR}=$ likelihood ratio. For definitions of other abbreviations, see Table 1.

$\dagger$ The value could not be determined due to division by zero. 
work is the first report in which the persistence of parasites in the myocardium has been demonstrated in a significant number of living patients with chronic disease, making it possible to correlate the presence of parasites with the clinical, serologic, and histopathologic findings that characterize chagasic myocarditis.

This fact also shows the importance of the study of EMB specimens in seropositive individuals, which could increase the possibility of detecting heart abnormalities not detected by noninvasive methods such the electrocardiogram and cineventriculogram. In fact, our results confirm the previous findings that normal ECGs in seropositive individuals is not indicative of a healthy myocardium in individuals with chronic disease, ${ }^{15}$ as judged by the presence of different degrees of necrosis, inflammatory infiltrates, and fibrosis in patients clinically classified as ChM/IA (28.6\%) and ChM/ IB $(14.3 \%) .{ }^{14}$ These signs of myocarditis were always confirmed by the detection of persistent $T$. cruzi amastigote tissue forms by the PAP technique or the parasite genome by the PCR. This fact suggests that although the number of parasites is low in chronic Chagas' disease, damage to the cardiac muscle is constantly occurring. This also indicates that persistent $T$. cruzi amastigotes detected in patients with chronic disease have the same biological capability of damaging the myocardium as those present during the acute phase of the disease.

These conclusions are supported by the histopathologic findings that demonstrate that myocarditis in patients with chronic disease appears to be a continuous process associated with necrosis, inflammatory infiltrates, and fibrosis, which progressively act and continue after the acute phase, where myocarditis is always observable, ${ }^{2,6}$ to the chronic phase, where it is detected in patients at different stages of the disease (ChM/IA to ChM/III). These findings in chronic Chagas' disease reflect what is commonly found in leishmaniasis, where parasite persistence appears to be a characteristic of the species of the genus Leishmania, as judged by their tendency to persist after clinical resolution of the disease. ${ }^{29}$ This fact, which is observed in acquired immunodeficiency syndrome-associated diseases, shows that an infection can remain asymptomatic or show relapses at different times in immunodepressed individuals.

These findings appear to cast some doubts on the existence of what has so far been called the indeterminate phase of Chagas' disease, which has been recognized as a symptomless period in the absence of parasites. This phase in the context of our results appears to have no justification, considering the almost constant parasite persistence in the myocardium and the constant myocarditis found in patients with chronic disease at different degrees of clinical complication and times after $T$. cruzi infection.

Based on the results of this study, we conclude that the drugs currently used for treating Chagas' disease are able to keep the disease in check by reducing the parasite population circulating in the peripheral blood, with subsequent improvement in the clinical condition of the patients. However, they are unable to eliminate the entire parasite population, part of which is found as amastigote tissue forms responsible for clinical relapse when immunodepression occurs.

Finally, due to the lack of effectiveness of drugs currently available to prevent colonization and persistence of $T$. cruzi tissue forms in the myocardium of patients with chronic disease, as demonstrated in the present work, we strongly recommend the immediate testing of drugs with long-term effects on $T$. cruzi populations, such as those used by Urbina and others in experimental models. ${ }^{30}$

Acknowledgments: We are indebted to Professor I. Woodward for careful review of the manuscript, and Marcos Aguilera and Nelly Paredes for technical assistance.

Financial support: This work was supported by Consejo de Desarrollo Cientifico, Humanístico y Tecnológico, Universidad de Los Andes, grants CDCHT-ULA-C-743-95AA (Nestor Añez) and 0-4696-07-A (Gloria Percoco), and Consejo Nacional de Investigaciones Científicas y Tecnológicas grants SI-95000889 (Nestor Añez) SI95000524 (Jose Luis Ramirez), and IAAE RLA6026 (Palmira Guevara).

Authors' addresses: Nestor Añez, Gladys Crisante, Agustina Rojas, and Nestor Gonzalez, Universidad de Los Andes, Facultad de Ciencias, Departamento de Biologia, Mérida, 5101 Venezuela. Hugo Carrasco and Carmen Fuenmayor, Instituto de Cardiologia and Departamento de Anatomia Patologica, Hospital Universitario de Los Andes, Mérida, 5101, Venezuela. Henry Parada, Unidad de Cardiologia, Hospital Luis Razetti, Barinas, Venezuela. Gloria Percoco, Instituto de Investigaciones Odontológicas, Facultad de Odontologia, Universidad de Los Andes, Mérida, 5101, Venezuela. Rafael Borges, Instituto de Estadistica Aplicada y Computación, Facultad de Economia, Universidad de Los Andes, Mérida, Venezuela. Palmira Guevara and Jose Luis Ramirez, Groupo de Genética Molecular, Facultad de Ciencias, Universidad Central de Venezuela, Caracas, Venezuela.

Reprint requests: Nestor Añez, Universidad de Los Andes, Facultad de Ciencias, Departamento de Biologia, Mérida, 5101, Venezuela.

\section{REFERENCES}

1. Rocha A, Meneses ACO, da Silva AM, Ferreira MS, Nishioka SA, Burgarelli MKN, Almeida E, Turcato Jr G, Metze K, Lopes ER, 1994. Pathology of patients with Chagas' disease and acquired immunodeficiency syndrome. Am J Trop Med Hyg 50: 261-268.

2. Añez N, Carrasco H, Parada H, Crisante G, Rojas A, Gonzalez N, Ramirez JL, Guevara P, Rivero C, Borges R, Scorza JV, 1999. Acute Chagas' disease in western Venezuela: a clinical, seroparasitologic, and epidemiologic study. Am J Trop Med Hyg 60: 215-222.

3. Breniere SF, Yaksic N, Telleria J, Bosseno MF, Noireau F, Winker P, Sanchez D, 1997. Immune response to Trypanosoma cruzi shed acute phase antigen in children from an endemic area for Chagas' disease in Bolivia. Mem Inst Oswaldo Cruz 92: 503-507.

4. Medrano-Mercado N, Luz MRMP, Torrico F, Tapia G, Van Leuven F, Araujo-Jorge TC, 1996. Acute phase proteins and serologic profiles of chagasic children from an endemic area in Bolivia. Am J Trop Med Hyg 54: 154-161.

5. Rassi A, Luquetti AD, Rassi Jr A, Rassi SG, Rassi AG, 1992.Chagas disease clinical features. Wendel S, Brener Z, Carnargo ME, Rassi A, eds. Chagas Disease (American Trypanosomiasis): Its Impact on Transfusion and Clinical Medicine. São Paulo: ISBT Brazil '92, 81-101.

6. Parada H, Carrasco H, Añez N, Fuenmayor C, Inglessis I, 1997. Cardiac involvement is a constant finding in acute Chagas' disease: a clinical, parasitological and histopathological study. Int J Cardiol 60: 49-54.

7. Laranja FS, Dias E, Nóbrega G, Miranda A, 1965. Chagas' disease: a clinical, epidemiologic and pathologic study. Circulation 14: 1035-1060.

8. Oliveira SF, Pedrosa RC, Nascimento JHM, Carvalho ACC, Masuda MO, 1997. Sera from chronic chagasic patients with complex cardiac arrythmias depress electrogenesis and conduction in isolated rabbit hearts. Circulation 96: 2031-2037. 
9. Almeida HO, Gobbi H, Teixeira VPA, Araujo WF, Fernandes PA, 1984. Aspectos da miocardites em chagásicos crônicos com "megas" e sem "megas" com insuficiência cardiaca. Rev Soc Bras Med Trop 17: 81-88.

10. Tavares-Neto J, 1990. Correlação do peso do coração de chagásico e controles com algumas caracteristicas anatomopatológicas. Rev Pat Trop 19: 25-34.

11. Jones EM, Colley DG, Tostes S, Lopes ER, Vnencak-Jones CL, McCurley TL, 1993. Amplification of Trypanosoma cruzi DNA sequence from inflammatory lesions in human chagasic cardiomyopathy. Am J Trop Med Hyg 48: 348-357.

12. Brener Z, 1987. Pathogenesis and immunopathology of chronic Chagas' disease. Mem Inst Oswaldo Cruz 82: 205-213.

13. Barbosa AA, Andrade ZA, 1984. Identificaçao do Trypanosoma cruzi nos tecidos extracardiacos de portadores de myocardite crónica chagásica. Rev Soc Bras Med Trop 17: 123-126.

14. Carrasco H, Parada H, Guerrero L, Duque M, Duran D, Molina C, 1994. Prognostic implications of clinical, electrocardiographic and hemodynamic findings in chronic Chagas' disease. Int J Cardiol 43: 27-38.

15. Carrasco H, Palacios E, Scorza C, Molina C, Inglessis G, Mendoza R, 1987. Clinical, histochemical and ultrastructural correlations in septal endomyocardial biopsies from chronic chagasic patients. Am Heart J 113: 716-724.

16. Barbosa AJA, 1985. Metodo immunocitoquimico para a identificação de amastigotas do Trypanosoma cruzi em cortes histológicos de rotina. Rev Inst Med Trop Sao Paulo 27: 293297.

17. Aretz HT, Billigharn ME, Edwards WD, 1987. Myocarditis: a histopathological definition and classification. Am J Cardiovasc Pathol 1: 3-14.

18. Fuenmayor CE, Carrasco H, Arriaga A, Molina C, 1997. Proposición de una nueva clasificación para la evaluación de pacientes con miocarditis crónica chagásica. Adv Cardiol 17: $59-66$.

19. Novak EM, De Mello MP, Gomez HBM, Galindo I, Guevara P, Ramirez JL, da Silveira, JF, 1993. Repetitive sequences in ribosomal intergenic spacer of Trypanosoma cruzi. Mol Biochem Parasitol 60: 273-280.

20. Gonzalez N, Galindo I, Guevara P, Novak E, Scorza JV, Añez
N, Da Silveira JF, Ramirez JL, 1994. Identification and detection of Trypanosoma cruzi by using a DNA amplification fingerprint obtained from the ribosomal intergenic spacer. $J$ Clin Microbiol 32: 153-158.

21. Zingales B, Pereira MES, Oliveira RP, Almeida KA, Umezawa ES, Souto RP, Vargas N, Cano MI, Da Silveira JF, Nehme NS, Morel CL, Brener Z, Macedo A, 1997. Trypanosoma cru$z i$ genome project: biological characteristics and molecular typing of clone CL Brener. Acta Trop 68: 159-173.

22. Cohen J, 1960. A coefficient of agreement for nominal scale. Educ Phyc Meas 20: 37-46.

23. Landis JR, Koch GG, 1997. The measurement of observer agreement to categorical data. Biometrics 33: 159-174.

24. Jaeschke R, Gordon H, Guyyat R, Sackett DI, 1994. Users' guides to medical literature. III. How to use an article about diagnostic test. What are the results and will they help me in caring for my patients? JAMA 271: 703-707.

25. Britto C, Cardoso MA, Vanni CMM, Haslocher-Moreno A, Xavier SS, Oelemann W, Santoro A, Pirmez C, Morel CM, Wincker P, 1995. Polymerase chain reaction detection of Trypanosoma cruzi in human blood samples as a tool for diagnosis and treatment evaluation. Parasitology 110: 241-247.

26. Rossi MA, 1990. Microvascular changes as a cause of chronic cardiomyopathy in Chagas' disease. Am Heart J 120: 233 236.

27. Colley DG, Howard MJ, 1991. The fundamental nature of Chagas' disease: a review provided by immune responses and idiotypes. Jpn J Trop Med Hyg 19: 175-190.

28. Higuchi ML, Brito T, Reiss MM, Barbosa AJA, Belloti G, Pereira-Barreto AC, Pileegi F, 1993. Correlation between Trypanosoma cruzi parasitism and myocardial inflammatory infiltrate in human chronic chagasic myocarditis: light microscopy and immunohistochemical findings. Cardiovasc Pathol 2: $101-106$

29. Ramirez JL, Guevara P, 1997. Persistent infections by Leishmania (Viannia) braziliensis. Mem Inst Oswaldo Cruz 92: 333-338.

30. Urbina JA, Payares G, Molina J, Sanoja C, Liendo A, Lazardi K, Piras MM, Piras R, Perez N, Wincker P, Ryley JF, 1996. Cure of short-and long-term experimental Chagas' disease using DO870. Science 273: 969-971. 